\title{
Case study on foundation aberration of a river-crossing bridge in Taiwan
}

\author{
Helsin Wang ${ }^{\text {i) }}$ and Ju-Jiang Hung ${ }^{\text {ii) }}$ \\ i) Senior Engineer, Institute of Bridge Engineering, CECI, 27F, No.185, Section 2, Sinhai Road, Taipei 10637, Taiwan. \\ ii) Professor Emeritus, Department of Civil Engineering, National Taiwan University, No.1, Section 4, Roosevelt Road, Taipei 10617, \\ Taiwan.
}

\begin{abstract}
A field investigation reported progressively severe scour around a bridge river-crossing PC bridge in southern Taiwan after a series of typhoons and storms. Layout misalignment was found on caissons up to 1.7 meters from their designate positions. A retrofit project was executed with concrete to integrate substructures and caissons as one structural element. Unfortunately, embedded caissons were exposed their upper portion on 6 piers in different severities. Failure retrofitting developed as structural discontinuities on 3 piers. Such a deficiency could impinge on the toppling issue of superstructure in case of occurrence of critical flooding or earthquake. A substructural stability analysis indicated its structural stability lying on the unsafe side on the most severe structural detrimental pier for the pier bottom was partially attached atop a caisson without any protection or repair. Finally, temporary substructural retrofitting was suggested to improve the weak linking between pier and caisson.
\end{abstract}

Keywords: bridge, scour, foundation aberration, toppling

\section{INTRODUCTION}

Scour was reported as the major cause of bridge failure in the U.S.A. (Brandon and Yadlosky, 2011; Lee, 2013). Similarly, in Taiwan, failure causes of bridges are highly associated with scour and hydrological migration (Lin, 2012). For example, Typhoon Morakot caused the most severe hydrological change which caused damage on 130 highway bridges in August, 2009 (CECI, 2009). Due to available budgets and the huge expense required for maintenance, limited funds are focused on bridges rated with highest priority for maintenance, based on an efficient and rapid assessment process. Currently, a scour inspection (draft) code for river-crossing bridges in Taiwan has being newly developed to guide inspection types, levels, frequencies, evaluation items, and stage of implementation (CECI, 2011). Visual inspection was served as a rapid and inexpensive inspection of scour potential first. Detailed inspections review structural, geotechnical, environmental, and hydrological conditions on questionable bridges during the flood season.

\section{ROUTINE INSPECTION AND SPECIAL INSPECTION}

A pre-stressed concrete two-lane bridge consisted of 15 spans with a total length of 450 meters and crossed over the Tzewen Stream in southern Taiwan, as shown in Fig. 1. The bridge constructed in 1988 was repeatedly found with progressively severe foundation exposure after a series of typhoons and storms. Through such a developing deterioration did not cause any loss in life or possession in past flooding, it still was the weakest traffic linking spot for nearby local townships in case of flooding or earthquake. A new bridge construction was always suggested to replace the current so-called old bridge by local commuters and residents.

The current web-based Taiwan Bridge Management System (TBMS), the most complete bridge database in Taiwan, archived biennial visual inspection data since 2000 and also provided as an official appraisal basis for highway bridge agencies. The historic visual inspection frequently indicated the target bridge as good condition with minor deficiencies, such as slight spalling on concrete railing, partially damaged expansion joints, drainage clogging on few spans, and insufficient concrete covering on partial superstructures. The inspection contractors never reported any channel migration and scour threat issues on this bridge. Significantly, there is recognition contradictory existing between inspection contractors and local public. However, the county government decided to positively response people's need to re-build a new bridge regardless of the inspection results.

The TBMS database shown that the identical inspection contractor was required to execute an in-situ 
special inspection after earthquake scale $\mathrm{M}=6.4$, less than 40 kilometers far in distance, in March, 2010. Ironically, the identical inspection team finally pointed out severe deficiencies on bridge substructure, like exposed foundation, broken piers, and settlement, occurred around the main channel, and also assigned this bridge on the bridge retrofitting list; however, still rated the waterway as safety condition.
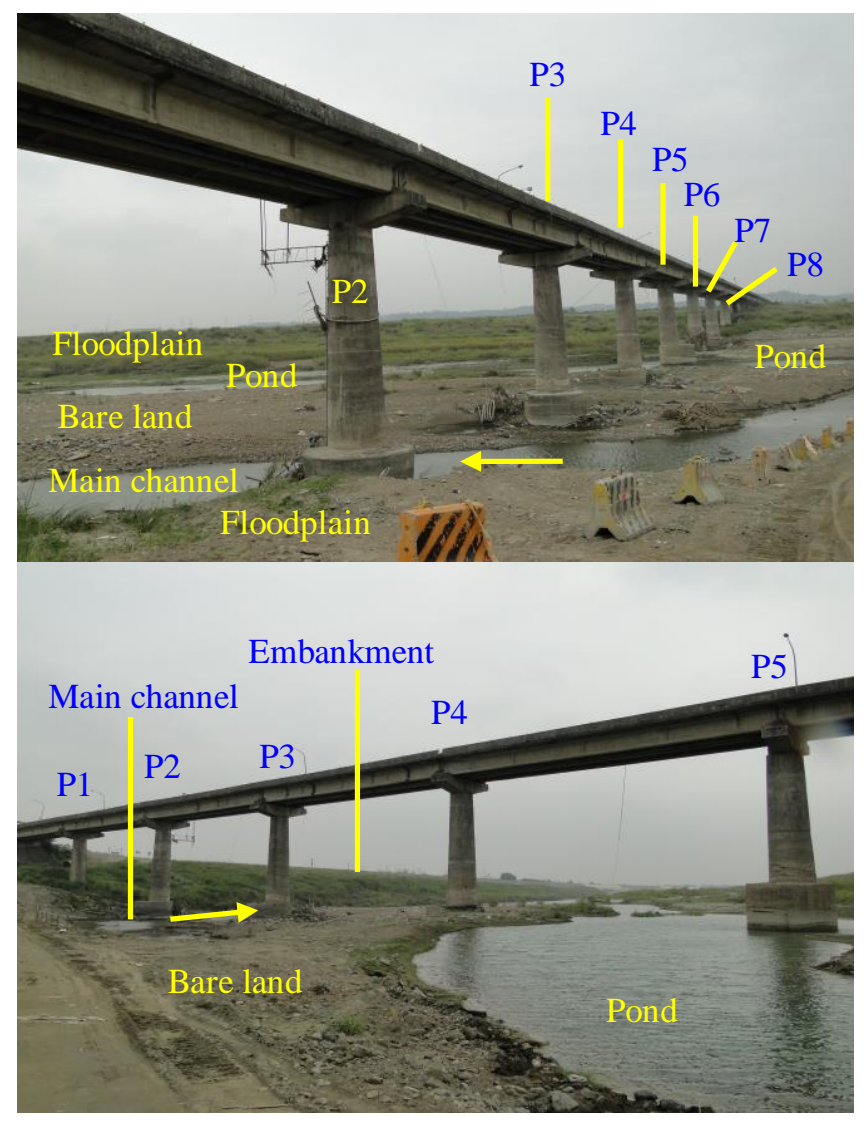

Fig. 1. Bridge crossing over the main channel.

The TBMS database shown that the identical inspection contractor was required to execute an in-situ special inspection after earthquake scale $M=6.4$, less than 40 kilometers far in distance, in March, 2010. Ironically, the identical inspection team finally pointed out severe deficiencies on bridge substructure, like exposed foundation, broken piers, and settlement, occurred around the main channel, and also assigned this bridge on the bridge retrofitting list; however, still rated the waterway as safety condition.

An updated drafting bridge visual inspection and evaluation manual has been announced to guide inspectors and code detailed findings item by item in Taiwan (Yau et al., 2010). The bridge headquarters in the national level also annually provided relevant inspection training courses for all bridge agencies and inspection contractors. However, the quality control (QC) and quality assurance (QA) of bridge inspection operation were continuously criticized and found as insufficient to poor level once detailed professional investigations were launched on damaged bridges (Wang and Wang, 2014). For its inconsistency concerns were frequently found in the bridge inspection recording and rating, therefore, visual inspection information partially coded or overlooked the severity of scour threat on bridge piers.

\section{INVESTIGATION AND ITS FINDINGS}

Another conventional field investigation was launched in response to earthquake scale $\mathrm{M}=6.8$ in eastern Taiwan 5 months after Typhoon Morakot event in 2009. The migration of the main channel was frequently moving between Piers P2 and P7 in Figure 1. Its sandy riverbed was overall degraded and local scour existed around some piers in Fig. 2. There were several fatal deficiencies found at its substructures and foundations at the main channel section. Its original embedded caissons were exposed their upper portion on some piers from P2 to P7 in different severities (Figs. 2 to 7). Drifting woody debris was rafted on the upstream side of piers P2, P6, and P7, as shown in Figs. 3, 4, and 7.

Based on known information, bridge foundations, herein as caissons, were constructed separately from its substructure and superstructure. Since the misalignment of caisson layout led to out of their designate positions, the centroids of caissons could not match the corresponding centroid positions of substructures. Therefore, retrofitting with concrete was used to diminish the discontinuity between substructures and caissons for structural safety on piers P2, P3, P5, P6, and $\mathrm{P} 7$, and all caissons were also embedded beneath river sands (Figs. 2 to 4 ).

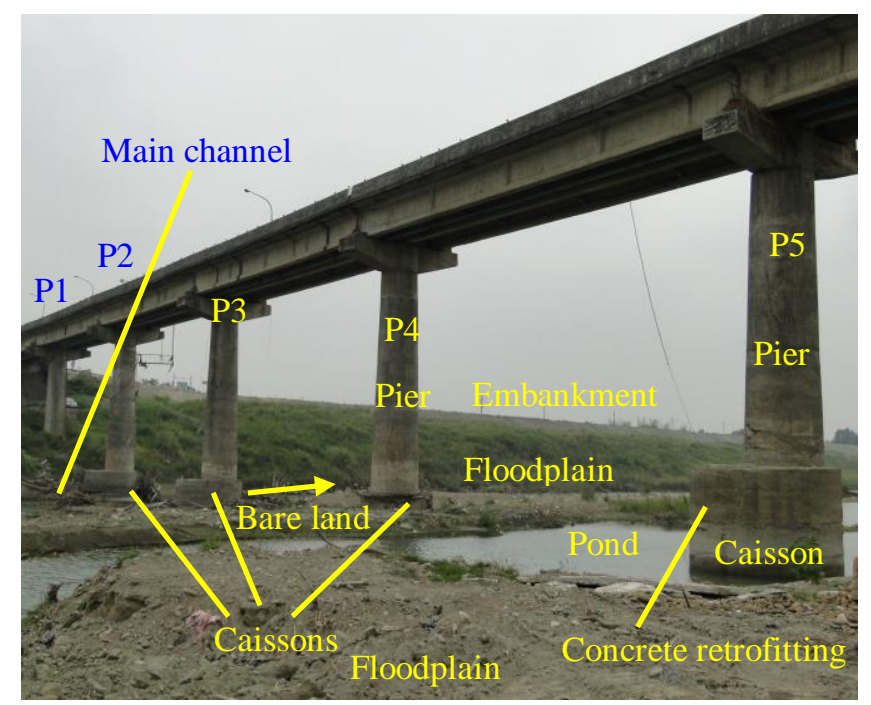

Fig. 2. Foundation exposure at the main channel.

Unfortunately, the substructural retrofitting was not performed and left unprotected on pier P4 for excessive layout deviation. The survey findings also pointed out that degrading foundation aberration 
significantly developed as discontinuities existing between piers and caissons on piers P2, P4, and P7. Their poor retrofitting condition, even no rehabilitation, was exposed after long-term flood-induced scour and riverbed degradation. A horizontal cold joint was identified on pier P2 and 20-cm lateral movement was existing between the retrofitted substructure and caisson, possible caused by flooding or earthquake (Fig. $3)$.

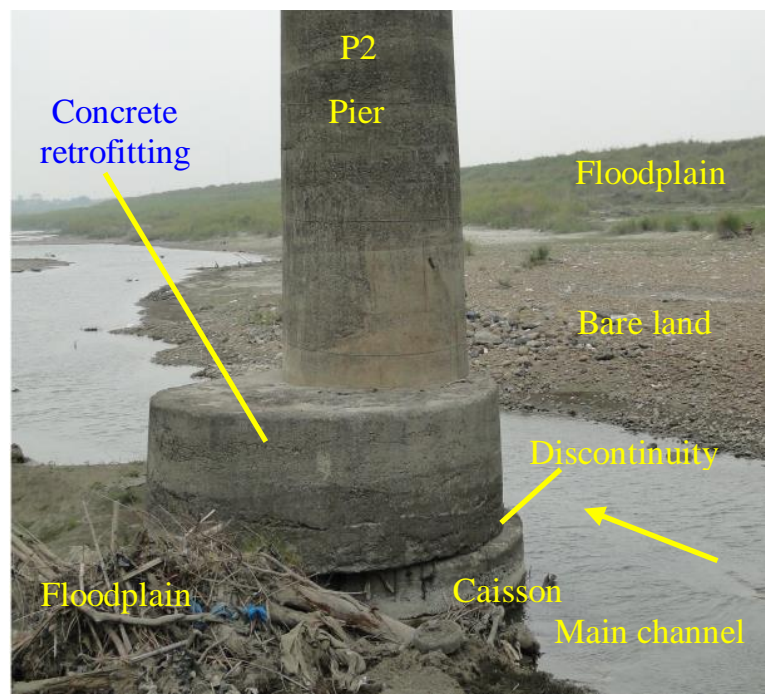

Fig. 3. Full-through discontinuity found on P2 foundation.

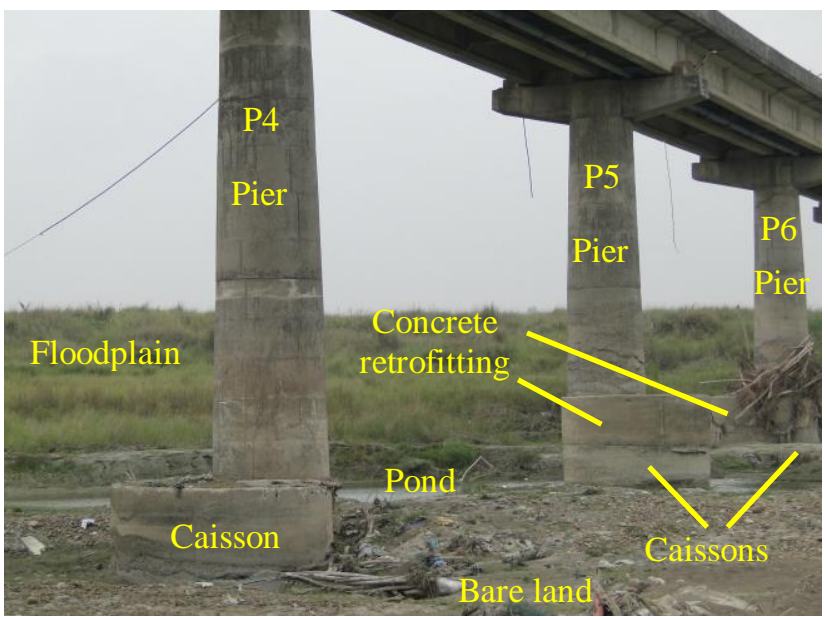

Fig. 4. Scour-induced foundation exposure (upstream side).

Pier P4 had the most severe structural detrimental for its substructural pier bottom partially attached atop a caisson without any protection or repair for years (Figs. 5 and 6). The outer deviation of the pier is measured up to $34 \mathrm{~cm}$ away from the caisson edge. Pier P7 experienced throughout cracking existing between the retrofitted substructure and caisson (Fig. 7). These foundation out-of-alignments and poor quality of retrofitting during construction could present the weakest link if without proper rehabilitation. Such a severe structural deficiency could impinge on the safety of bridge in case of occurrence of critical scour or earthquake.

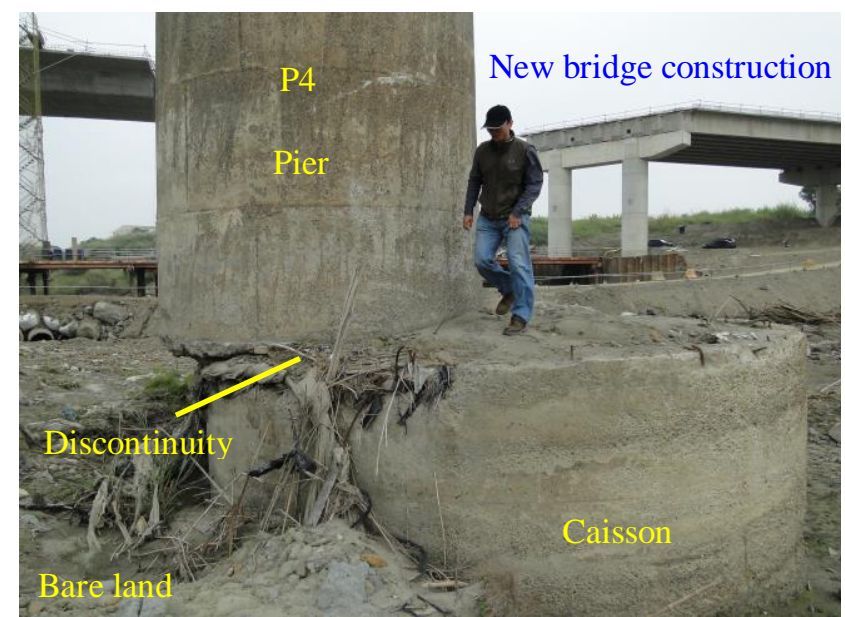

Fig. 5. Layout deviation on P4 foundation (downstream side).

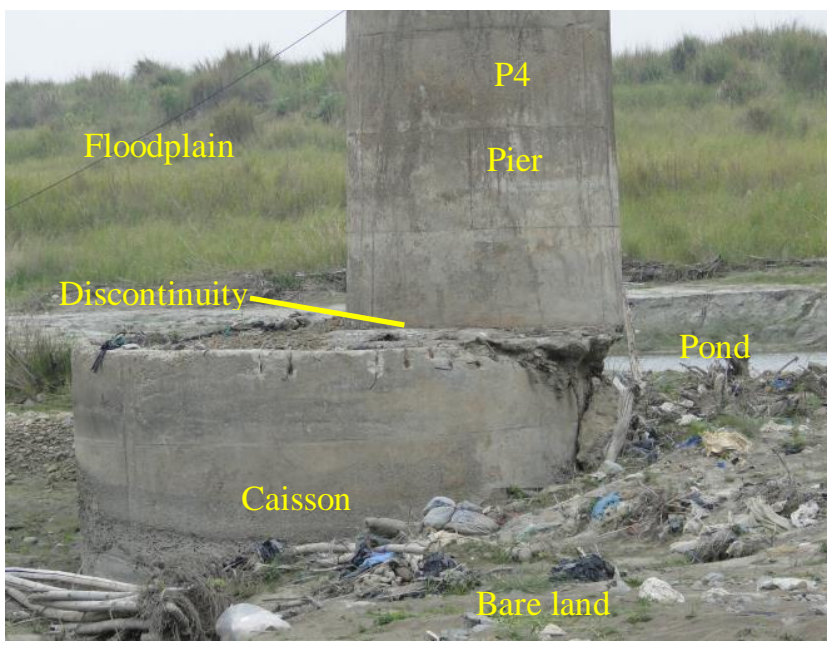

Fig. 6. P4 partially hanging out of caisson beneath (upstream side).

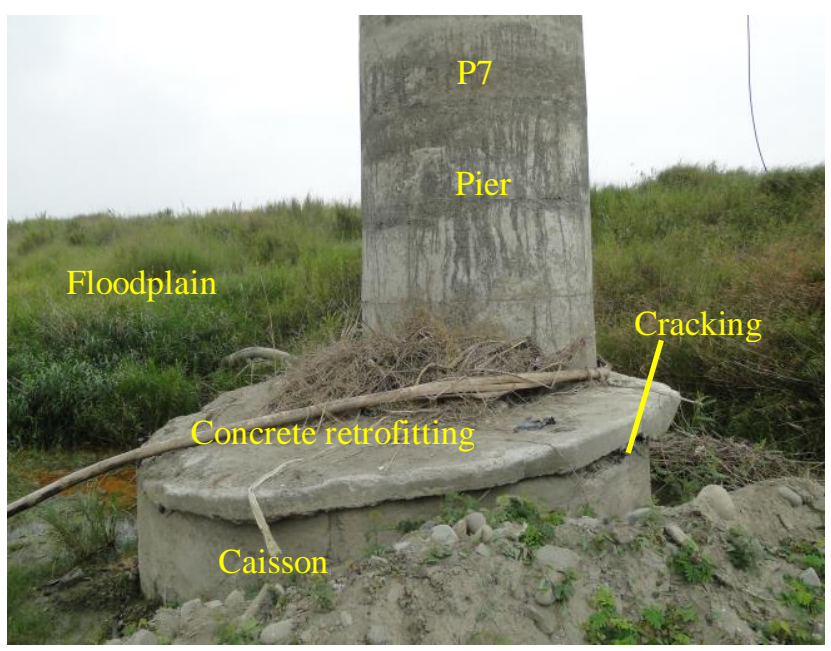

Fig. 7. Throughout cracking on P7 foundation.

\section{TOPPLING STABILITY ANALYSIS AND SUGGESTION}

Since P4 has the most severe structural detrimental 
and could be completely separated from caisson beneath (Fig. 6), a pseudo-static toppling stability analysis is conducted on this pier and superstructure subjected to horizontal earthquake force. Resistant and thrust moments are selected around two critical points, toppling around caisson edge and pier edge; i.e. Case A and Case B, respectively (Fig. 8).

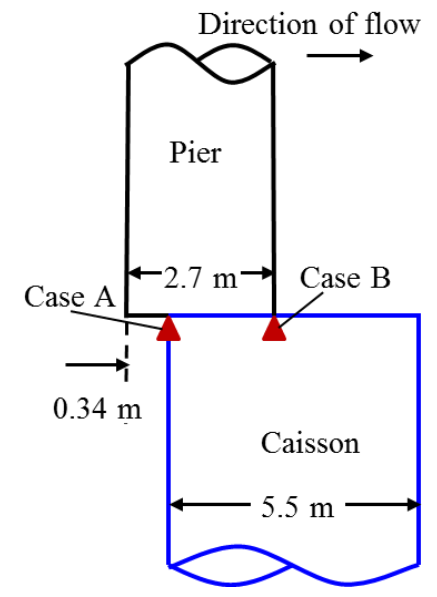

Fig. 8. Two cases of toppling stability analysis.

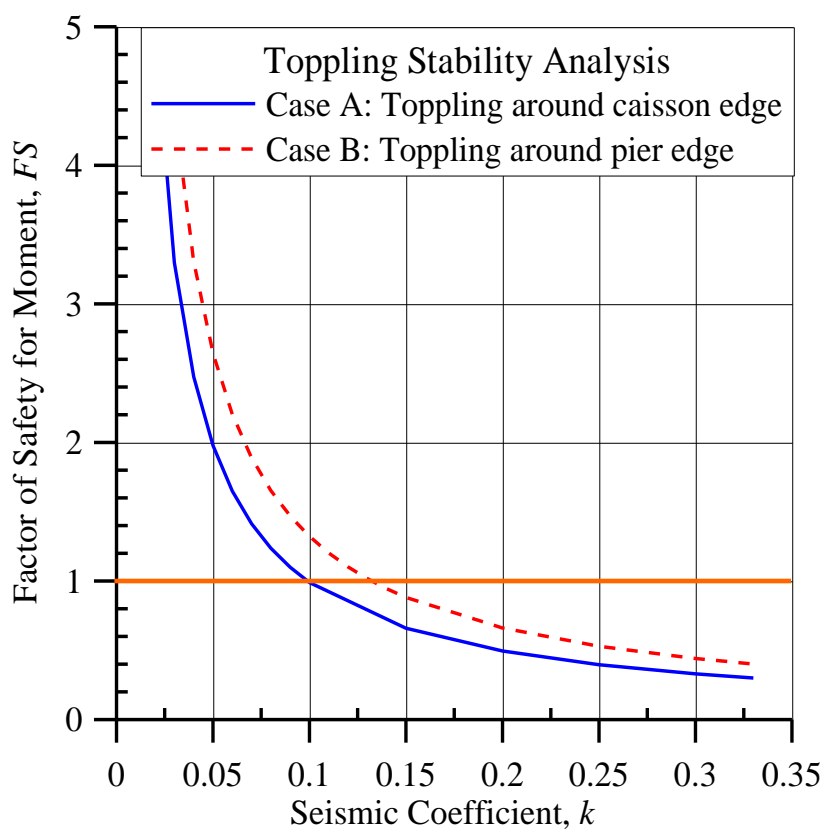

Fig. 9. Relation between seismic coefficient and factor of safety.

The resistant force comes from the dead load of one superstructural span and P4. As neglecting the friction from adjacent two spans and flood thrust, the thrust force is simplified as its horizontal seismic force with seismic coefficient $(k)$ ranging from $0.01 \mathrm{~g}$ to $0.33 \mathrm{~g}$, the maximum design value. The analysis result indicates that factor of safety $(F S)$ decreases as seismic coefficient $(k)$ increases for both cases as shown on Fig. 9. Originally, the structural integrity is designed for caisson, pier, and superstructure, and its horizontal seismic force can be effectively taken and passed down into its substructure, foundation, and surrounding soils. However, a structural discontinuity exists between the pier and caisson, its maximum horizontal resistant force is lowered down around $0.1 \mathrm{~g}$ far below its design value. Its structural stability is lying on the unsafe side, and such instability could impinge on the toppling issue of superstructure in case of occurrence of earthquake.

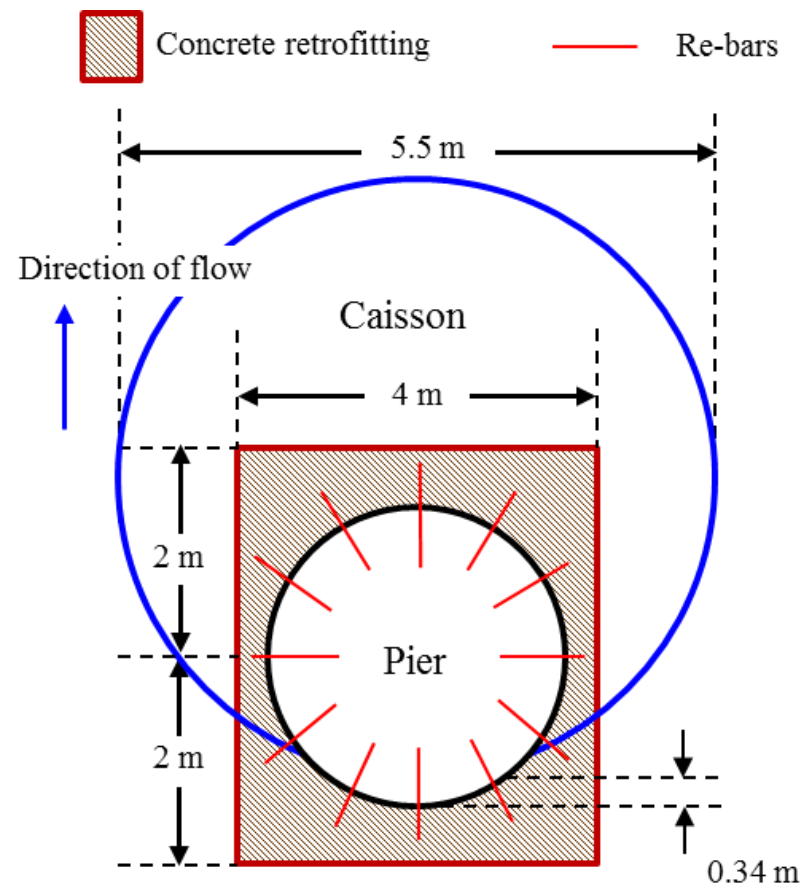

(a) Top view

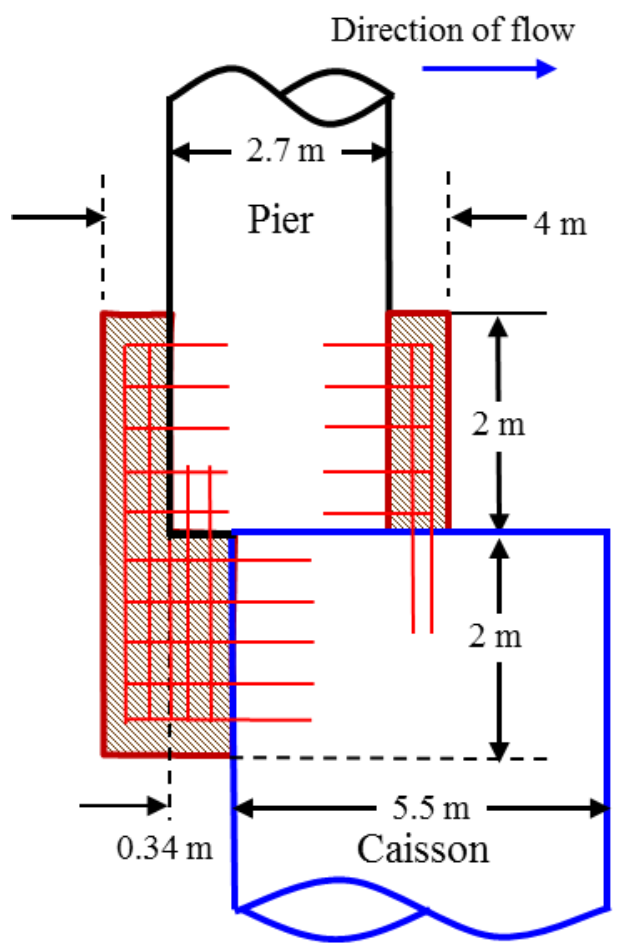

(b) Elevation view

Fig. 10. Suggested temporal substructural retrofitting on P4. 
In order to prevent bridge toppling, temporary substructral retrofitting is suggested to improve the weak linking between pier and caisson. As can be seen in Fig. 10, a $4 \mathrm{~m} \times 4 \mathrm{~m} \times 4 \mathrm{~m}$ concrete block is expected to cross the discontinuity zone and bond the pier and caisson as a single structural element. Installing radial and vertical re-bars can provide extra force transition mechanism between concrete block and pier or caisson. Its toppling pivot can be moved downward into underground portion, and surrounding lateral earth pressure can also increase toppling resistance against horizontal seismic force.

\section{CONCLUSIONS}

Several fatal deficiencies, including scour-induced exposure and misalignment, were found at river-crossing PC bridge foundations. The original embedded caissons were exposed their upper portion on Piers P2 to P7 to a certain extent. Caisson misalignment during construction caused structural discontinuity weak planes existing between substructures and caissons on 3 piers. Due to excessive layout deviation, pier P4 has 0.34 meters misalignment out of its beneath caisson edge without any substructural retrofitting. Toppling stability analysis indicates that current P4 is lying on the unsafe side under the condition of horizontal seismic force. Once its horizontal seismic force is more than 0.1 times dead load of the superstructure and pier, the bridge could lead to toppling around the caisson edge. A temporal substructural retrofitting is suggested to improve the weak linking between substructure and caisson on P4.

\section{REFERENCES}

1) Brandon, W.C. and Yadlosky, J.M. (2011): Framework for Improving Resilience of Bridge Design, FHWA Report No. FHWA-IF-11-016, Federal Highway Administration, Washington, D.C., U.S.A.

2) China Engineering Consultants, Inc. (CECI) (2009): An Investigation Memoir for Bridge Failures in Typhoon Morakot, China Engineering Consultants, Inc. (CECI), Taipei, Taiwan. (in Chinese)

3) China Engineering Consultants, Inc. (CECI) (2011): A Study on Establishing the Scour Inspection Code (Draft) for River-Crossing Bridge Foundations, Institute of Transportation (IOT), Ministry of Transportation and Communications (MOTC), Taipei, Taiwan. (in Chinese)

4) Lee, G.C. (2013): Development of reliability-based bridge limit states for extreme loads- Recent progress, Proceedings of the $9^{\text {th }}$ US-Taiwan Bridge Engineering Workshop, Taoyuan, Taiwan, 15-30.

5) Lin, C. (2012): Bridge Hydraulics- in View of Natural Disaster, Scientific and Technical Publishing, Taipei, Taiwan. (in Chinese)

6) Ministry of Transportation and Communications (MOTC) (2009): Design Specifications for Highway Bridges, MOTC, Taipei, Taiwan. (in Chinese)

7) Wang, H. and Wang, C.-Y. (2014): Identification shallow foundation bridge scour based on routine inspection data, Journal of Engineering, National Chung Hsing University,
25(2), 49-63. (in Chinese)

8) Yau, N.-J., Chen, M.-C., Yeh, C.-J., Tsai, H.-C., and Liao, H.-K. (2010): A Study on Drafting the Bridge Visual Inspection and Evaluation Manual, Report to the Institute of Transportation (IOT), Ministry of Transportation and Communications (MOTC), Taipei, Taiwan. (in Chinese) 